Research Article

\title{
Experimental Study on Spray Characteristics of Gasoline/ Hydrogenated Catalytic Biodiesel under GCI Conditions
}

\author{
Wenhua Yuan $\mathbb{D}^{1},{ }^{1}$ Jingjing Liao $\left(\mathbb{D},{ }^{1}\right.$ Bei $\mathrm{Li}^{2}{ }^{2}$ and Wenjun Zhong ${ }^{2}$ \\ ${ }^{1}$ Department of Mechanical and Energy Engineering, Shaoyang University, Shaoyang 422000, China \\ ${ }^{2}$ School of Energy Power Engineering, Jiangsu University, Zhenjiang 212013, China \\ Correspondence should be addressed to Wenhua Yuan; ywh6308@163.com
}

Received 6 November 2019; Revised 7 January 2020; Accepted 4 February 2020; Published 11 May 2020

Guest Editor: Dezhi Zhou

Copyright (C) 2020 Wenhua Yuan et al. This is an open access article distributed under the Creative Commons Attribution License, which permits unrestricted use, distribution, and reproduction in any medium, provided the original work is properly cited.

The new blended fuel (gasoline/hydrogenated catalytic biodiesel) is expected to address the cold start problem under low temperature of gasoline compression ignition due to its excellent ignition performance. Additionally, its spray behavior as the combustion boundary condition could have a direct impact on the characteristics of subsequent combustion. Therefore, the objective of this study is to reveal the effects of hydrogenated catalytic biodiesel/gasoline on the spray characteristics under various ambient conditions. As a significant index of spray characteristics, the spray penetration was achieved by applying Mie scattering methods under nonevaporation and evaporation conditions on a constant volume combustion chamber. In addition, the experimental results were compared against the calculated values of the models. As demonstrated by the results, a better spray performance can be achieved by the blended fuel than diesel and hydrogenated catalytic biodiesel. In respect of spray penetration, there is almost no difference among the three fuels under the ambient temperature of $323 \mathrm{~K}$. Nevertheless, the blended fuel is lower than that of hydrogenated catalytic biodiesel and diesel when the ambient temperature is $434 \mathrm{~K}$ and $523 \mathrm{~K}$. Moreover, the blended fuel is the first to reach the stable state, and the hydrogenated catalytic biodiesel is earlier than diesel for the spray penetration. Meanwhile, the spray model is identified as suitable for the blended fuel.

\section{Introduction}

With the increasingly severe environmental problems and more stringent vehicle emission regulations, energy-efficient and low-emission internal combustion engines have attracted a great deal of attention in the most recent years. In order to achieve high efficiency and low emission for internal combustion engines, it has prompted many researchers to develop a variety of novel combustion modes such as homogeneous compression ignition (HCCI) [1, 2], premixed compression ignition (PCCI) $[3,4]$, partial premixed compression ignition (PPC) $[5,6]$, reactive controlled compression ignition (RCCI) [7], and gasoline compression ignition (GCI) $[8,9]$. Especially, the GCI, as a direct injection compression ignition technology of gasoline in the cylinder, is able to control the formation of the mixed gas through the fuel injection strategy and to shape an appropriate mixture concentration stratification before ignition, thus exercising control over ignition time and ignition phase. Compared with the conventional engine technologies, it took advantage of the high octane number and volatility of gasoline to achieve full mixing of fuel before ignition, which could achieve excellent combustion performance and low pollution emission $[6,10]$. However, the excessively high octane number would cause difficulties in ignition at low load and high rate of pressure rise at high load. Therefore, it is possible to rely on fuel design to realize GCI combustion mode.

In recent years, plenty of research studies have been conducted on the GCI combustion. A success has been achieved in extending the GCI mode to idle condition with No. 87 antiexplosive gasoline by Kolodzieg et al. [11]. Jia et al. [12] performed a study on the combustion emission characteristics of three different alternatives to gasoline fuels in compression ignition mode on a single-cylinder fourstroke diesel engine. As revealed by the results, TRFDIB fuel is an ideal gasoline alternative fuel. Ma et al. [13] investigated 
the liquid-phase penetration and flame lift-off length and soot volume fraction distribution using gasoline/diesel fuel with different blending ratios. They determined that the increase of gasoline proportion in gasoline-diesel blends has shown suppression effect in emissions. The experiment was performed by Adams et al. [14] on a single-cylinder highpressure common rail direct-injection light diesel engine with a compression ratio of 16.6 so as to explore the combustion and emission characteristics of soybean oil methyl ester biodiesel and RON87 gasoline blends under compression ignition mode. As indicated by the results, the ignition performance of gasoline could be affected by the addition of biodiesel with less volatility and higher cetane number. Meanwhile, the difficulty in ignition at low load can be reduced. For gasoline direct injection compression ignition, plenty of experimental studies have been performed $[15,16]$, which led to the discovery that the direct injection compression ignition of gasoline could achieve a high thermal efficiency while reducing the emission of NOx and soot.

For GCI combustion mode, despite plenty of studies that have been conducted to evaluate the combustion emission characteristics of gasoline-diesel or biodiesel blends, the density difference between gasoline and diesel fuel remains significant, and the existence of miscible mixing stability problems restricts the development of gasoline direct injection combustion technology. Considering that HCB has different fuel properties compared to diesel such as high cetane number, low density, sulfur content, and no oxygen, it also possesses similar chemical structure to diesel. Therefore, in this paper, the experiment on the spray characteristic of gasoline/hydrogenated catalytic biodiesel mixture was conducted on constant volume based on the analysis conducted of the properties and spray combustion characteristics shown by hydrogenated catalytic biodiesel in the early stage of team.

It is well known that fuel spray and evaporation characteristics have an important effect on combustion process and final engine performance and emission. In this paper, the aim is to gain a further understanding of the mixing process of gasoline/hydrogenated catalytic biodiesel blend fuel and provide experimental evidence of the spray model. The spray characteristics between diesel, hydrogenated catalytic biodiesel, and gasoline/hydrogenated catalytic biodiesel blended fuels were compared and analyzed. Moreover, a detailed spray database was established for modeling validation to provide theoretical support for the application of blended fuel in engine combustion.

\section{Experimental System and Test Conditions}

2.1. Experimental Setup. A study on fuel sprays was performed in an optically visible constant volume combustion chamber, which was comprised of constant volume combustion chamber, high-pressure common rail fuel injection system, intake and exhaust system, data acquisition system, heating system, etc. The details can be attained in the previous research [17].
2.2. Experimental Methods. In the present study, the liquid phase was measured through the use of the Mie scattering imaging method under inert condition and with the help of the experimental apparatus as illustrated in Figure 1. As the source of lighting to visualize fuel spray, two white LEDs with a $140 \mathrm{~W}$ power were placed on both lateral windows, respectively. The high-speed digital camera was a Photron SA-Z with a vertical light source. The lens matching the phase machine was Nikon Micro-NIKKOR, the maximum aperture and focal length of which were 2.8 and $105 \mathrm{~mm}$, respectively. Besides, the imaging speed was set to $40,000 \mathrm{fps}$ with exposure time of $23.39 \mu \mathrm{s}$, and the resolution was $512 * 1024$. The details on the test method can be referenced in the previous study $[18,19]$.

\subsection{Fuels and Test Matrix}

2.3.1. Fuel Properties. In this paper, HCB was primarily obtained from waste cooking oil by applying the hydrodeoxygenation technology and the constituents of biodiesel were identified by conducting analysis with the assistance of gas chromatography-mass spectrometer (GC-MS). For the detailed result of hydrogenated catalytic biodiesel by GCMS, one can refer to Shang et al. [20]. The main components of the biodiesel include $n$-pentadecane, $n$-hexadecane, and n-heptadecane with saturated alkane structure, accounting for $8.98 \%, 23.94 \%$, and $47.38 \%$, respectively. The fuel properties used in this study were supplied by Jiangsu Provincial Institute of Product Quality Supervision and Inspection and were compliant with GB/T20828-2015 and GB19147-2016 as the national standards. The full data are indicated in Table 1, which indicates that the fuel density, dynamic viscosity, and distillation of HCB are significantly lower when compared to pure diesel.

2.3.2. Test Matrix. In view of the previous research [21], this study mainly compared the spray characteristics of $70 \%$ gasoline and 30\% hydrogenated catalytic biodiesel blend fuel (G70H30), hydrogenated catalytic biodiesel, and diesel oil, where "G" in G70H30 indicates gasoline, "H" denotes hydrogenated catalytic biodiesel, "D100" refers to diesel oil, and "HCB" stands for hydrogenated catalytic biodiesel, with the purpose of identifying whether gasoline/hydrogenated catalytic biodiesel blends can be used in gasoline compression combustion mode. The experimental conditions are presented in Table 2. The spray penetration of three kinds of fuels was analyzed comparatively under nonevaporation and evaporation conditions by changing the ambient temperature. Fuel injection was repeated for 10 times under each working condition for improvement to the reliability of the experimental results, and the interval time between each injection was set as $10 \mathrm{~s}$.

2.4. Image Processing. Image processing represents a crucial part of the analysis of experimental data. In this study, the digital images captured by high-speed camera were processed by using MATLAB software. For the Mie scattering 


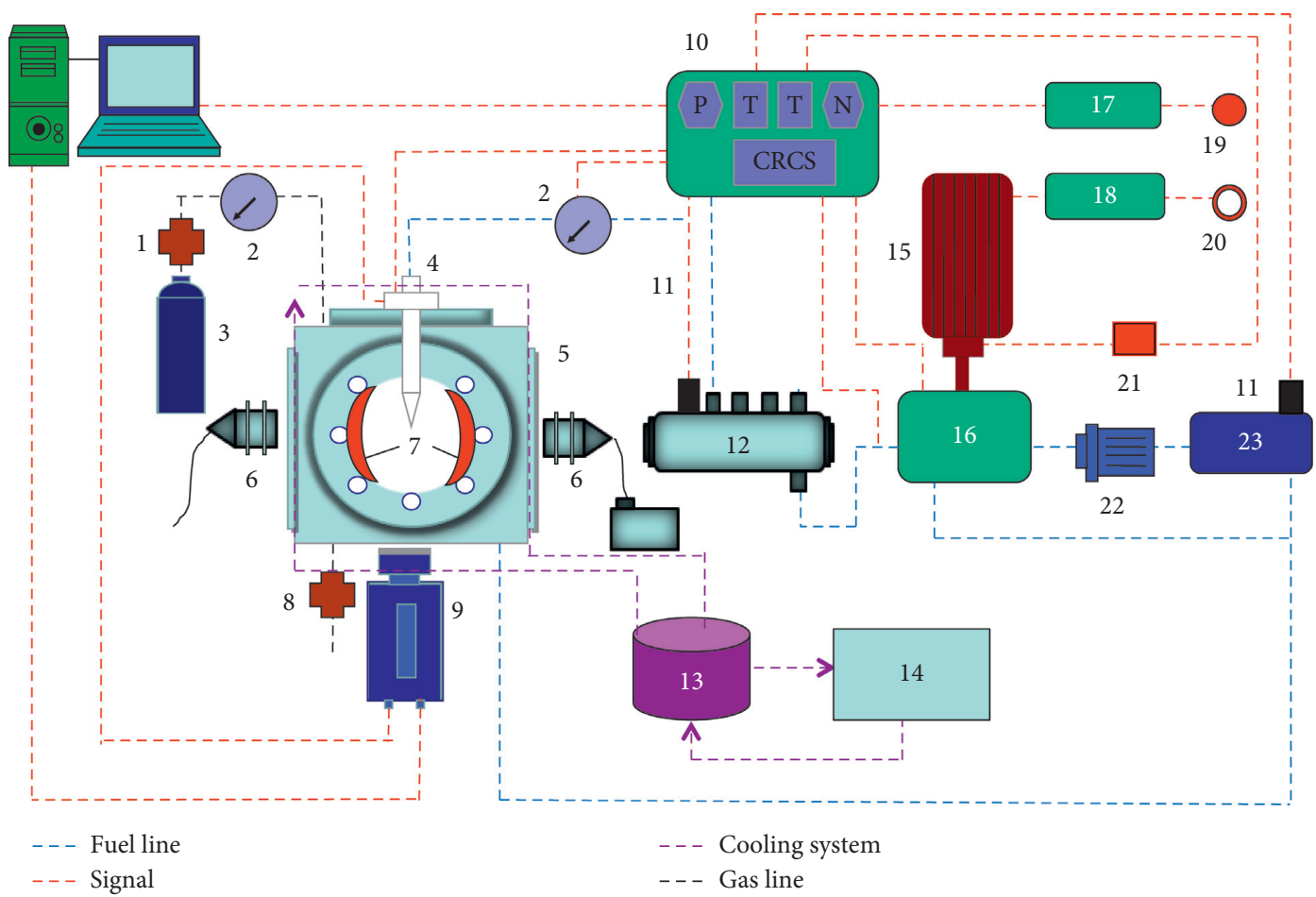

Figure 1: Schematic of Mie scatter (1, pressure reducing valve; 2, pressure meter; 3, nitrogen gas; 4, injector; 5, constant volume; 6, LED light source; 7, heating panels; 8 , exhaust valve; 9 , CCD camera; 10 , high-pressure common rail system; 11, thermoelement; 12 , common rail; 13 , cooling water tank; 14, condenser; 15, electric motor; 16, high-pressure fuel pump; 17, switchboard; 18, transducer; 19, sensor switch; 20, potentiometric control unit; 21, speed sensor; 22, fuel filter; 23 , fuel tank).

Table 1: Properties of experiment fuels.

\begin{tabular}{lccc}
\hline Fuel properties & Diesel & HCB & Gasoline \\
\hline Density $\left(20^{\circ} \mathrm{C}\right) \mathrm{kg} / \mathrm{m}^{3}$ & 832 & 791 & 762 \\
Cetane number & 49 & 103 & 14 \\
Viscosity $\left(40^{\circ} \mathrm{C}\right) \mathrm{mm}^{2} / \mathrm{s}$ & 5.8 & 3.3 & 0.62 \\
Oxygen content $(\mathrm{m} / \mathrm{m})$ & 0 & 0 & $<2.7$ \\
Sulfur content $(\mathrm{mg} / \mathrm{kg})$ & $<10$ & 4.3 & $<10$ \\
Boiling point $(10 \%) /{ }^{\circ} \mathrm{C}$ & - & - & 40 \\
Boiling point $(50 \%) /{ }^{\circ} \mathrm{C}$ & 300 & 303 & 111 \\
Boiling point $(90 \%) /{ }^{\circ} \mathrm{C}$ & 355 & 315 & 162 \\
PAHs content $(\mathrm{mg} / \mathrm{mg}) \%$ & 11 & 0 & - \\
Low heating value $(\mathrm{M} / \mathrm{kg})$ & 38 & 44 & 42.7 \\
\hline
\end{tabular}

TABLe 2: Test matrix.

\begin{tabular}{lccc}
\hline Parameters & \multicolumn{3}{c}{ Nonevaporation Evaporation } \\
\hline Ambient environment $T_{a}(\mathrm{~K})$ & 323 & 423 & 523 \\
Ambient pressure $p_{a}(\mathrm{MPa})$ & 5 & 5 & 5 \\
Ambient density $\rho_{a}\left(\mathrm{~kg} / \mathrm{m}^{3}\right)$ & 51.13 & 39.80 & 32.19 \\
Injection pressure $p_{i}(\mathrm{MPa})$ & 100 & 100 & 100 \\
Fuels & $\mathrm{D} 100$ & $\mathrm{HCB}$ & $\mathrm{D} 100$ \\
\hline
\end{tabular}

image, taking the background as the static, the average value of the first 18 images without fuel injection was taken as the background. Then, each image was removed from the background to get the spray area, and the $30 \%$ value of the peak gray value was treated as the threshold to generate a binary image. Subsequently, the spray profile was cleaned using a filter, as shown in Figure 2. The distance between the injector tip to the farthest axial location of spray boundary was expressed as the spray penetration.

\section{Results and Discussion}

3.1. Spray Morphology and Spray Penetration. As shown in Figure 3, the influence that ambient temperature has on the tip penetration of the three fuels spray (D100, HCB, and G70H30) is exhibited under fuel injection pressure of $100 \mathrm{MPa}$ and ambient density of $5 \mathrm{MPa}$. It can be seen from the figure that the three different fuels demonstrate similarly in penetration and dispersion behaviors with values of $323 \mathrm{~K}$ and $423 \mathrm{~K}$. When the temperature rises to $523 \mathrm{~K}$, the spray liquid phase of the G70H30 is shown to be shorter, which suggests that the mixed fuel has already undergone a substantial amount of fuel evaporation during this period. In addition, by comparing the spray at the proximal end of the nozzle with that at the lower end of the oil beam, a conclusion can be concluded that wrinkles and shedding disappear at the lower end of the spray oil beam, which is mainly attributed to the liquid fuel in the spray front area that undergoes the evaporation process from liquid to gas, thus leading to the loss of the spray liquid phase. On the other hand, the spray front will be turned into smaller particles with atomization, which would weaken the Mie scattering signal and result in the disappearance of folds.

In order for a deeper understanding as to the spray characteristics of the three fuels, a quantitative analysis was 


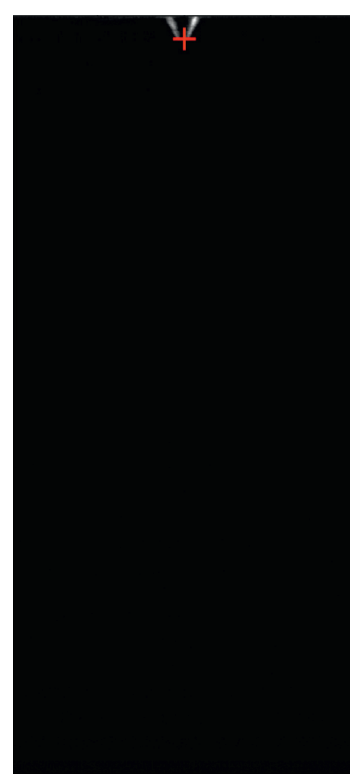

(a)

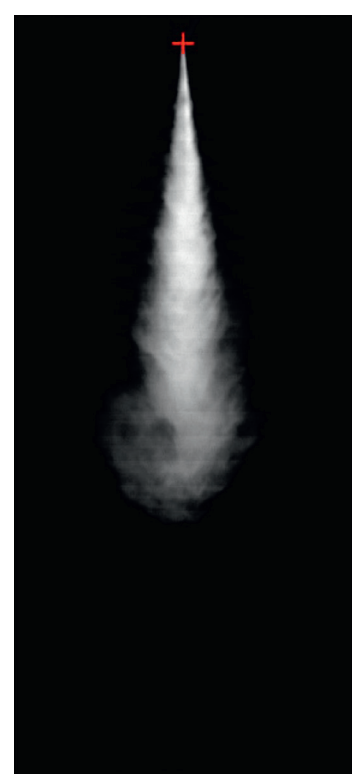

(b)

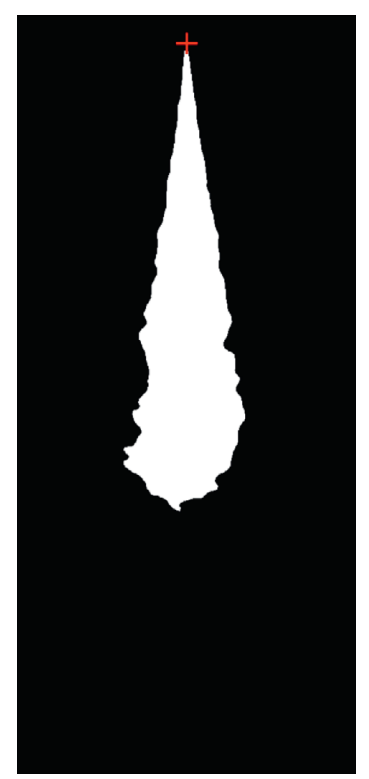

(c)

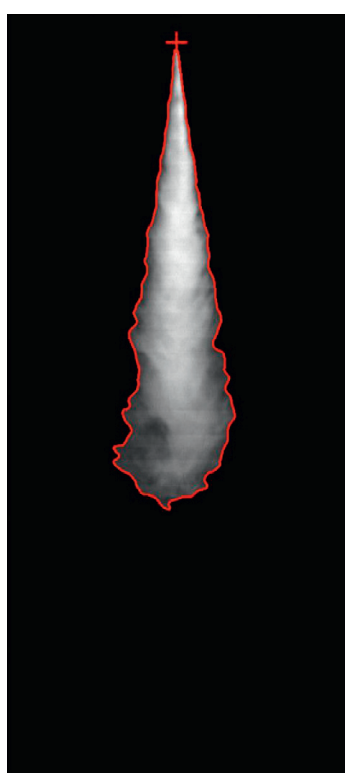

(d)

Figure 2: Image process for Mie scattering. (a) Average image for background. (b) Raw image subtracting background. (c) Binary image. (d) Filter image.
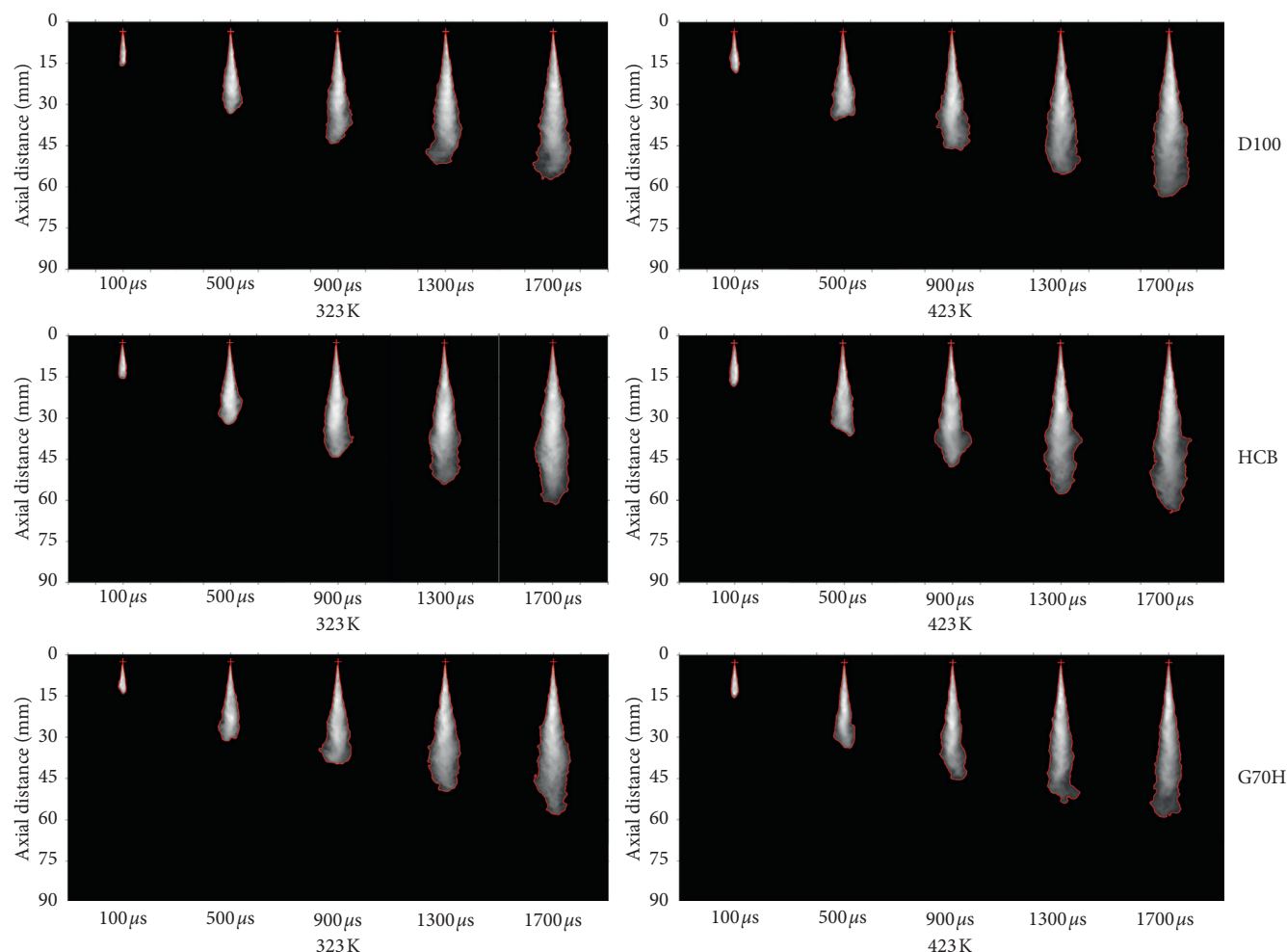

(a)

FIGURE 3: Continued. 

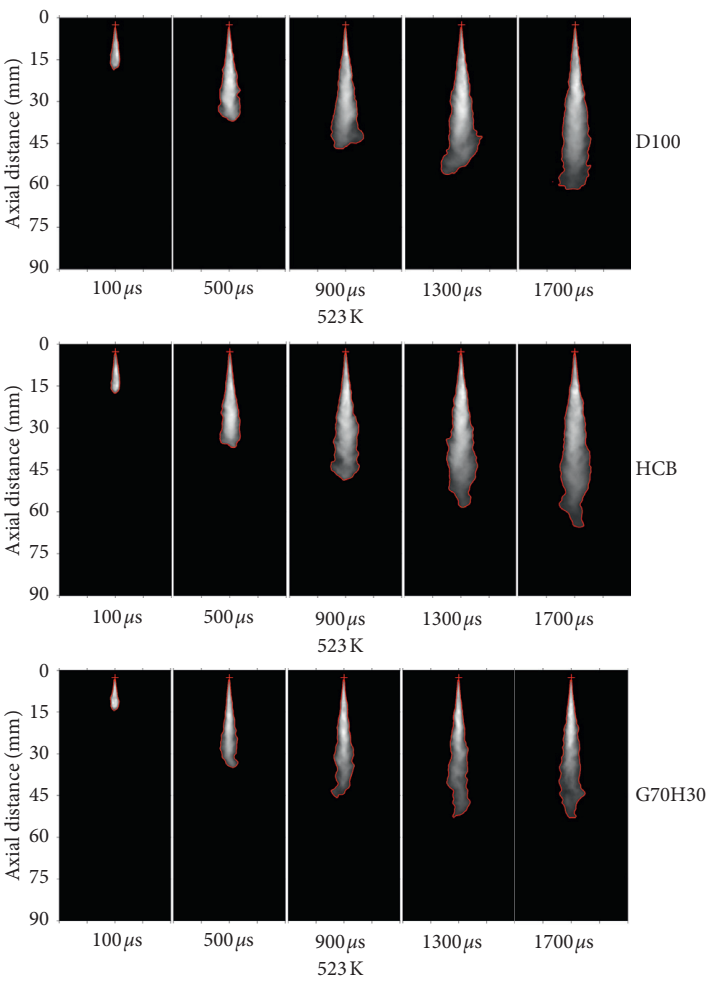

(b)

Figure 3: Liquid phase development versus time for D100, HCB, and G70H30 fuels under $323 \mathrm{~K}, 423 \mathrm{~K}$, and $523 \mathrm{~K}$.

conducted for the spray penetration for these fuels at varying ambient temperatures, as indicated in Figure 4. It can be discovered from the figures that there is a faster spray penetration of different fuels in advance of reaching a constant value and little fluctuation, which express a significant influence on the combustion efficiency of the diesel engine wall under the identical working conditions. At $323 \mathrm{~K}$ ambient temperature, with the fuels of D100, HCB, and G70H30, there is barely any difference between the spray penetration, and it basically increases over time. Gradually, the spray penetration reaches a certain stable value. Nevertheless, as the ambient temperature is on the rise, there is accordingly a more significant difference of stable value spotted between different fuels. When the ambient temperatures are $423 \mathrm{~K}$ and $523 \mathrm{~K}$, respectively, the spray penetration of the three fuels are broadly the same at the first few hundred microseconds, suggesting that the fuel passes through the same path prior to their evaporation. Then, after the passing of a few hundred microseconds, at every ambient temperature, D100 results in a significantly higher spray penetration than the blends, with the values of HCB slightly greater than the mixed fuels.

As revealed by the fuel properties listed in Table 1, due to the lower density, viscosity, and surface tension of gasoline compared to the other two fuels and the higher volatility that leads to faster fuel droplets breaking and evaporation process, G70H30 demonstrates a better spray atomization behavior and a shorter spray penetration. Moreover, when the ambient temperature reaches $523 \mathrm{~K}, \mathrm{G} 70 \mathrm{H} 30$ is the first to

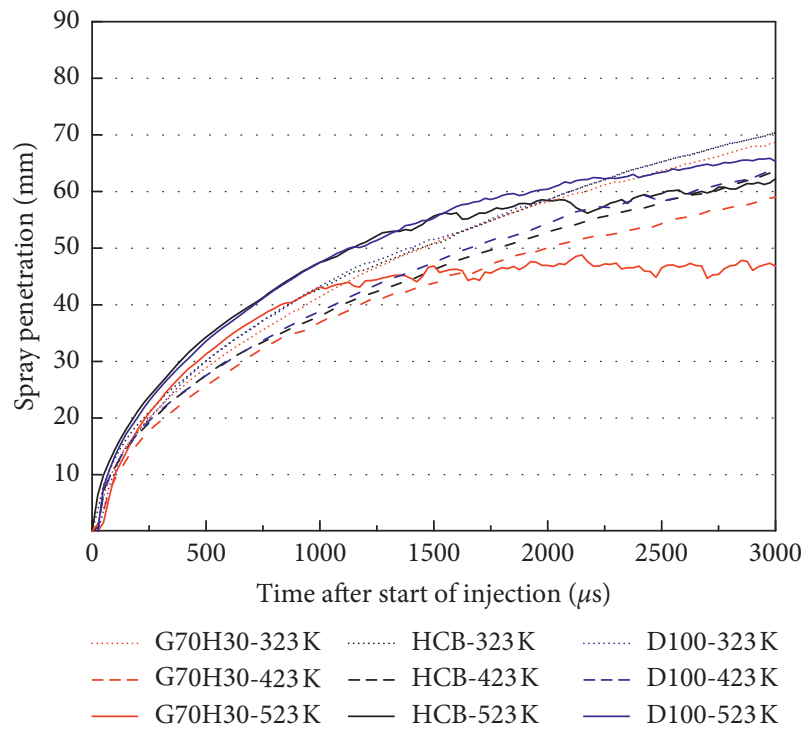

Figure 4: Liquid spray penetration versus time for D100, HCB, and $\mathrm{G} 70 \mathrm{H} 30$ fuels under different ambient temperatures.

reach a stable state, followed by HCB and D100, respectively, which is closely related to fuel distillation. The higher distillation temperature is followed by the longer time it takes for fuel spray to reach a stable state.

Perfect spray penetration leads to better air-fuel mixing, while too long liquid length leads to fuel wall impingement on the cylinder, which may increase soot emission and 
reduce engine efficiency. Therefore, compared with D100 and $\mathrm{HCB}, \mathrm{G} 70 \mathrm{H} 30$ demonstrates a more desirable spray characteristic, which is conducive to diesel engine gasoline compression ignition.

3.2. Spray Model. In order to follow up with the numerical calculation of spray combustion in gasoline compression ignition mode, the work of model verification was undertaken with consideration given to the experimental results, including model validation of the corresponding model equations under nonevaporation and evaporation conditions at three different temperatures.

\subsubsection{Theoretical Model}

(1) The Model under Nonevaporation. Plenty of research studies have provided the empirical expressions for the purpose of determining the spray characteristics of liquid jet depending on theoretical study and practical data on various oil fields [22]. As the spray has yet to be fully developed at this stage before the crushing, a peak occurs at the time when the spray starts to rupture. Hiroyasu and Arai [23] proposed a semiempirical formula for the variation of spray penetration over time under nonevaporation conditions combined with experimental data for two different regions before and after crushing.

$$
\begin{aligned}
S(t) & =K_{v} \sqrt{\frac{\Delta P}{\rho_{f}}} t, \quad 0<t<t_{\text {break }}, \\
S(t) & =K_{p} \sqrt{d_{n} t}\left(\frac{\Delta P}{\rho_{a}}\right)^{0.25}, \quad t>t_{\text {break }}, \\
t_{\text {break }} & =\frac{K_{\mathrm{bt}} \rho_{f} d_{0}}{\left(\rho_{a} \Delta P\right)^{0.5}},
\end{aligned}
$$

where $\rho_{f}, \rho_{a}, d_{0}$, and $\Delta P$ are fuel and ambient gas densities, orifice diameter, and the difference between the fuel injection pressure and ambient pressure, respectively; $t$ is the time after start of injection; and $K_{v}, K_{p}$, and $K_{\mathrm{bt}}$ are model constants. Specific values are exhibited in Table 3.

For the breaking time of three fuels, the dependent variables at three varieties of temperatures show broadly the same values. So, in this paper, $423 \mathrm{~K}$ is exemplified to obtain three fuel breaking times. In this paper, $423 \mathrm{~K}$ is exemplified to obtain three fuel breaking times, as indicated in Table 4. It can be observed in the table that Hiroyasu and Arai models differ greatly in respect of breaking time, and Arai models predict a shorter breaking time. In addition, the breaking time predicted by the two models shows that $\mathrm{G} 70 \mathrm{H} 30$ is the shortest, followed by $\mathrm{HCB}$, and D100 is the longest, which is largely attributed to the relationship between breakup time and fuel density.

(2) The Model under Evaporation. Based on the semiempirical formula suggested by Siebers [24], Desantes et al. [25] proposed a theoretical model in the terms of the conservation of momentum flux along the spray axis. Additionally,
TABle 3: Model constants for spray tip penetration.

\begin{tabular}{lcc}
\hline Model constants & Hiroyasu & Arai \\
\hline$K_{v}$ & 0.39 & 0.60 \\
$K_{p}$ & 2.95 & 3.36 \\
$K_{\mathrm{bt}}$ & 28.6 & 15.70 \\
\hline
\end{tabular}

TABLE 4: Break time of experiment fuels.

\begin{tabular}{lccc}
\hline Fuels & D100 & HCB & G70H30 \\
\hline Orifice diameter $(\mathrm{mm})$ & 0.12 & 0.12 & 0.12 \\
Ambient density $\left(\mathrm{kg} / \mathrm{m}^{3}\right)$ & 39.81 & 39.81 & 39.81 \\
Injection pressure $(\mathrm{MPa})$ & 100 & 100 & 100 \\
Ambient pressure $(\mathrm{MPa})$ & 5 & 5 & 5 \\
Hiroyasu breaking time $(\mu \mathrm{s})$ & 46.51 & 44.22 & 43.06 \\
Arai breaking time $(\mu \mathrm{s})$ & 14.35 & 13.64 & 13.29 \\
\hline
\end{tabular}

as the spray penetration was clearly restricted by the geometry of the nozzle orifice as well as environmental and spray conditions, there is a necessity for the spray cone angle to be taken into account [26]. Therefore, based on the formula of Siebers, the spray penetration under evaporation conditions was calculated by applying the following model equation [27]:

$$
\begin{gathered}
S(t) \propto\left(\frac{\rho_{f}}{\rho_{a}}\right)^{1 / 4} u_{0}^{1 / 2} d_{0}^{1 / 2} t^{1 / 2} \tan \left(\frac{\theta}{2}\right)^{-1 / 2}, \\
u_{0}=\frac{2\left(p_{f}-p_{a}\right)^{1 / 2}}{\rho_{f}} .
\end{gathered}
$$

From equations (4) and (5), we can get (6) as model equation:

$$
S(t)=\left(\frac{2\left(p_{f}-p_{a}\right)}{\rho_{a}}\right)^{1 / 4} d_{0}^{1 / 2} t^{1 / 2} \tan \left(\frac{\theta}{2}\right)^{-1 / 2},
$$

where $\rho_{f}$ and $\rho_{\mathrm{a}}$ are fuel and ambient gas densities, respectively; $d_{0}$ is orifice diameter, $t$ is time after start of injection; $p_{f}$ and $p_{a}$ are injection and ambient pressure, and $\theta$ is the spray angle.

3.2.2. Model Comparative Analysis. In this paper, the experimental data and the calculated values of the model were compared and analyzed by using formulas (2) and (6). Figure 5 shows the details on the comparison. It can be seen that the experimental statistics of D100 and HCB are consistent with the calculation results of model equation (1) under the nonevaporation situation. When G70H30 reaches $323 \mathrm{~K}$, the experimental value coincides with that of the calculated from the model equation (1). Especially, at the temperature of $423 \mathrm{~K}$, the experimental results conform well with the Hiroyasu model and model equation (1) only in the early stage of spray development, and the experimental value of the spray penetration is greater than estimated at the latter stage, which is speculated as associated with the low density and lower viscosity of gasoline. 


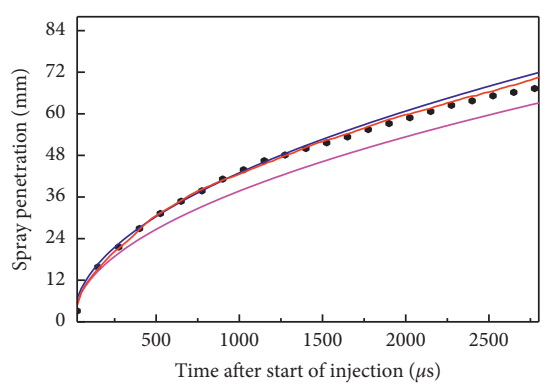

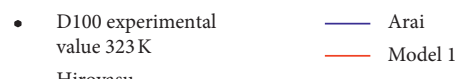

_ Hiroyasu
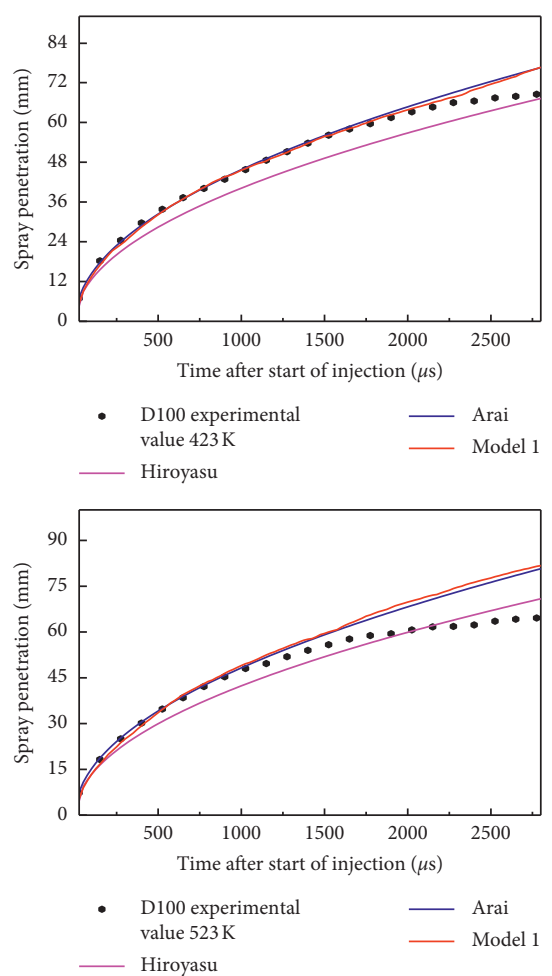

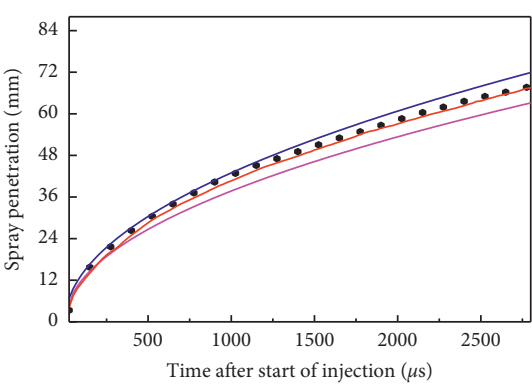

- HCB experimental _ Arai value $323 \mathrm{~K}$ — Hiroyasu

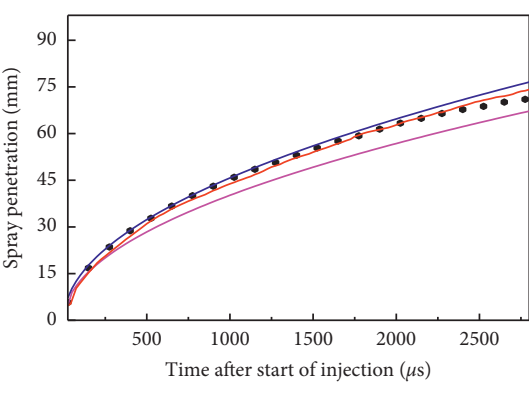

- HCB experimental value $423 \mathrm{~K}$

— Hiroyasu

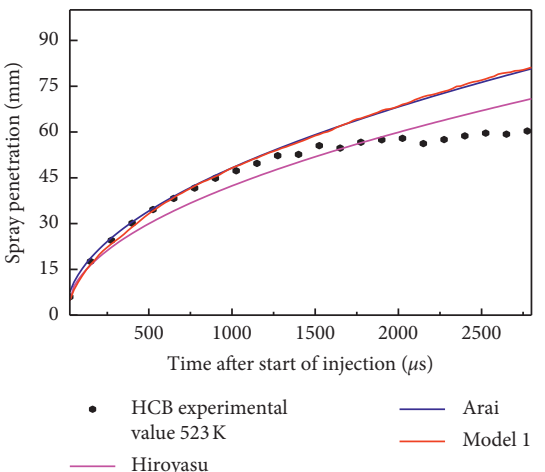

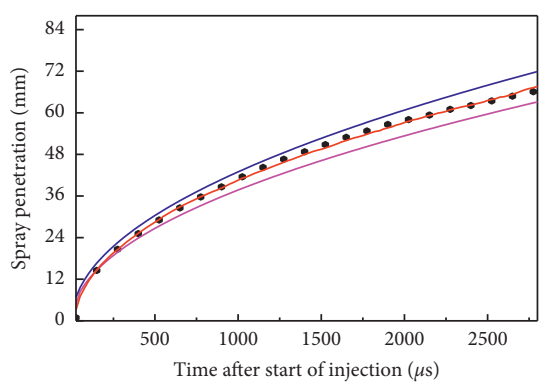

- G70H30 experimental __ Ara value $323 \mathrm{~K}$ - Hiroyasu

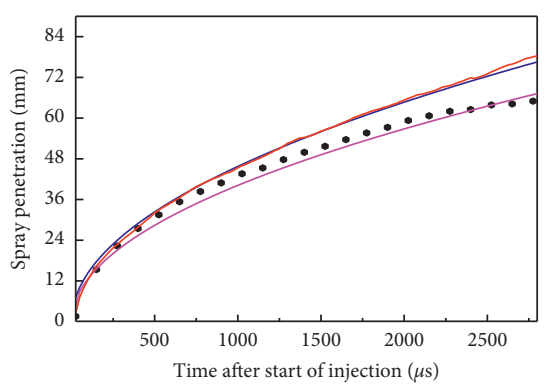

- $\mathrm{G} 70 \mathrm{H} 30$ experimental value $423 \mathrm{~K}$

- Arai — Hiroyasu

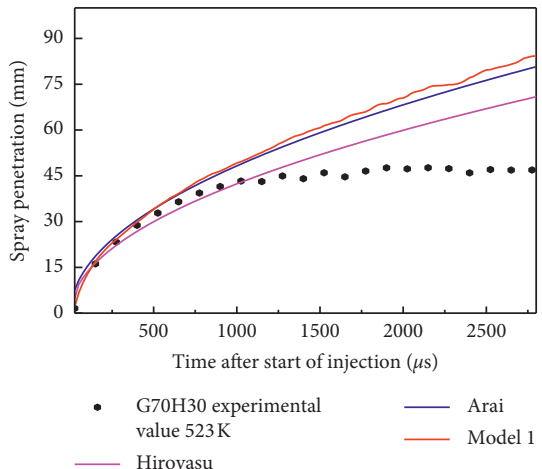

FIGURE 5: Comparison between experimental spray data and models for D100, HCB, and G70H30.

In the evaporation state, the experimental results of the three fuels in the early stage are in accordance with model 1, which is attributed to the spray penetration rate being faster than the evaporation rate. As a result of that, the difference of evaporation rate is yet to be reflected. Then, at the later stage, due to the different evaporation rates and faster evaporation rate than that of penetration, there is a difference of fitting, which suggests that the spray model is also applicable to the blended fuel G70H30. Moreover, in the nonevaporating state, the spray characteristics of three types of fuel can be predicted by applying model equation (1). In the late stage of evaporation, the evaporation model should be taken into consideration for analysis to improve the coincidence.

\section{Conclusion}

In this study, the Mie scattering technique was applied to study the spray characteristics of diesel, HCB, and G70H30 fuels under different ambient temperatures, the spray structures and the spray penetration were mainly analyzed and compared, and the model calculation results were obtained to perform validation. The observations can be summarized as follows:

(1) G70H30 has been successfully applied to the highpressure common rail system, and the wall impingement phenomenon will not occur in a smallbore engine. Besides, compared with diesel and HCB, G70H30 shows similarity spray characteristics which reveal the blending fuel can be used in the compression ignition combustion model.

(2) G70H30 is capable of achieving a superior spray performance compared to diesel and HCB and is applicable to compression ignition engine. Meanwhile, the atomization and evaporation are noticeably enhanced after the addition of gasoline, which is effective in facilitating the mixing of oil and gas, thus improving the combustion performance of the engine. 
(3) The spray model equation is also suitable for $\mathrm{G} 70 \mathrm{H} 30$. Based on the comparative analysis of experimental data and model calculation values, despite the model constant of model equation (1) as obtained under evaporation conditions, it is also applicable to the spray characteristics of three fuels in nonevaporation state. As for evaporation state, allowing for the evaporation and penetration rate, the evaporation model ought to be considered for a further improvement to the calculation formula in the latter stage of spray.

\section{Nomenclature}

\begin{tabular}{|c|c|}
\hline HCCI: & Homogeneous charge compression ignition \\
\hline PCC: & Premixed charge compression ignition \\
\hline PPC: & Partial premixed compression ignition \\
\hline RCCI: & Reactive controlled compression ignition \\
\hline GCI: & Gasoline compression ignition \\
\hline HCB: & Hydrogenated catalytic biodiesel \\
\hline G70H30: & $\begin{array}{l}70 \% \text { gasoline and } 30 \% \text { hydrogenated catalytic } \\
\text { biodiesel }\end{array}$ \\
\hline D100: & Pure diesel \\
\hline GB: & Gasoline/biodiesel blends \\
\hline H10: & $100 \%$ hydrogenated catalytic biodiesel \\
\hline NOx: & Nitrogen oxides \\
\hline$\rho_{f}$ & Fuel density $\left(\mathrm{kg} / \mathrm{m}^{3}\right)$ \\
\hline$\rho_{a}:$ & Ambient gas density $\left(\mathrm{kg} / \mathrm{m}^{3}\right)$ \\
\hline$d_{0}:$ & Orifice diameter $(\mathrm{mm})$ \\
\hline$\Delta p:$ & $\begin{array}{l}\text { The difference between the fuel injection } \\
\text { pressure and ambient pressure }(\mathrm{MPa})\end{array}$ \\
\hline$t:$ & The time after start of injection $(\mu \mathrm{s})$ \\
\hline $\begin{array}{l}K_{v}, K_{p}, \\
K_{\mathrm{bt}}:\end{array}$ & Model constants \\
\hline$p:$ & Ambient pressure $(\mathrm{MPa})$ \\
\hline$p_{f}$ & Injection pressure $(\mathrm{MPa})$ \\
\hline$\theta:$ & Spray angle $\left(^{\circ}\right)$ \\
\hline Ta: & Ambient environment $(\mathrm{K})$. \\
\hline
\end{tabular}

\section{Data Availability}

The data used to support the findings of this study are available from the corresponding author upon request.

\section{Conflicts of Interest}

The authors declare that they have no conflicts of interest.

\section{Acknowledgments}

This research was supported by the National Natural Science Foundation of China (no. 91541121) and the Postgraduate Innovative Research Project of Hunan Province (CX2018B814).

\section{References}

[1] A. Uyumaz, "An experimental investigation into combustion and performance characteristics of an HCCI gasoline engine fueled with n-heptane, isopropanol and n-butanol fuel blends at different inlet air temperatures," Energy Conversion and Management, vol. 98, pp. 199-207, 2015.

[2] B.-Q. He, J. Yuan, M.-B. Liu, and H. Zhao, "Combustion and emission characteristics of a n-butanol HCCI engine," Fuel, vol. 115, no. 1, pp. 758-764, 2014.

[3] R. Kiplimo, E. Tomita, N. Kawahara, and S. Yokobe, "Effects of spray impingement, injection parameters, and EGR on the combustion and emission characteristics of a PCCI diesel engine," Applied Thermal Engineering, vol. 37, pp. 165-175, 2012.

[4] A. J. Torregrosa, A. Broatch, A. García, and L. F. Mónico, "Sensitivity of combustion noise and NOx and soot emissions to pilot injection in PCCI Diesel engines," Applied Energy, vol. 104, pp. 149-157, 2013.

[5] Y. An, M. Jaasim, V. Raman et al., "Homogeneous charge compression ignition (HCCI) and partially premixed combustion (PPC) in compression Ignition engine with low octane gasoline," Energy, vol. 158, 2018.

[6] D. Han, A. M. Ickes, S. V. Bohac, Z. Huang, and D. N. Assanis, "Premixed low-temperature combustion of blends of diesel and gasoline in a high speed compression ignition engine," Proceedings of the Combustion Institute, vol. 33, no. 2, pp. 3039-3046, 2011.

[7] R. D. Reitz and G. Duraisamy, "Review of high efficiency and clean reactivity controlled compression ignition (RCCI) combustion in internal combustion engines," Progress in Energy and Combustion Science, vol. 46, pp. 12-71, 2015.

[8] C. Kavuri, J. Paz, and S. L. Kokjohn, "A comparison of Reactivity Controlled Compression Ignition (RCCI) and Gasoline Compression Ignition (GCI) strategies at high load, low speed conditions," Energy Conversion and Management, vol. 127, pp. 324-341, 2016.

[9] G. T. Kalghatgi, P. Risberg, and H. Ångström, "Partially premixed auto-ignition of gasoline to attain low smoke and low NOx at high load in a compression ignition engine and comparison with a diesel fuel," in Proceedings of theSAE Technical Paper Series, January 2007.

[10] M. Tuner, T. Johansson, H. Aulin et al., "Multi cylinder partially premixed combustion performance using commercial lightduty engine hardware," in Proceedings of the SAE 2014 International Powertrain, Fuels \& Lubricants Meeting, October 2014.

[11] C. Kolodziej, J. Kodavasal, S. Ciatti et al., "Achieving stable engine operation of gasoline compression ignition using 87 AKI gasoline down to idle," in Proceedings of the SAE 2015 World Congress \& Exhibition, SAE International, Detroit, Michigan, USA, April 2015.

[12] G. Jia, H. Wang, L. Tong, X. Wang, Z. Zheng, and M. Yao, "Experimental and numerical studies on three gasoline surrogates applied in gasoline compression ignition (GCI) mode," Applied Energy, vol. 192, pp. 59-70, 2017.

[13] X. Ma, L. Zheng, Z. Wang, and J. Wang, "An optical study on liquid-phase penetration, flame lift-off location and soot volume fraction distribution of gasoline-diesel blends in a constant volume vessel," Fuel, vol. 139, pp. 365-373, 2015.

[14] C. A. Adams, P. Loeper, R. Krieger, M. J. Andrie, and D. E. Foster, "Effects of biodiesel-gasoline blends on gasoline direct-injection compression ignition (GCI) combustion," Fuel, vol. 111, pp. 784-790, 2013.

[15] A. J. Torregrosa, A. Broatch, R. Novella, J. Gomez-Soriano, and L. F. Mónico, "Impact of gasoline and Diesel blends on combustion noise and pollutant emissions in Premixed Charge Compression Ignition engines," Energy, vol. 137, pp. 58-68, 2017.

[16] Y. Putrasari and O. Lim, "A study on combustion and emission of GCI engines fueled with gasoline-biodiesel blends," Fuel, vol. 189, pp. 141-154, 2017. 
[17] D. Li, Z. He, T. Xuan et al., "Simultaneous capture of liquid length of spray and flame lift-off length for second-generation biodiesel/diesel blended fuel in a constant volume combustion chamber," Fuel, vol. 189, pp. 260-269, 2017.

[18] W. Zhong, P. Tamilselvan, Q. Wang et al., "Experimental study of spray characteristics of diesel/hydrogenated catalytic biodiesel blended fuels under inert and reacting conditions," Energy, vol. 153, pp. 349-358, 2018.

[19] P. Tamilselvan, W. Zhong, T. Xuan et al., "Simultaneous study on spray liquid length, ignition and combustion characteristics of diesel and hydrogenated catalytic biodiesel in a constant volume combustion chamber," Renewable Energy, vol. 140, pp. 761-771, 2019.

[20] W. Shang, Z. He, Q. Wang et al., "Experimental and analytical study on capture spray liquid penetration and combustion characteristics simultaneously with Hydrogenated Catalytic Biodiesel/Diesel blended fuel," Applied Energy, vol. 226, pp. 947-956, 2018.

[21] W. Zhong, T. Pachiannan, Z. Li et al., "Combustion and emission characteristics of gasoline/hydrogenated catalytic biodiesel blends in gasoline compression ignition engines under different loads of double injection strategies," Applied Energy, vol. 251, p. 113296, 2019.

[22] M. Xu, Y. Cui, and K. Deng, "One-dimensional model on liquid-phase fuel penetration in diesel sprays," Journal of the Energy Institute, vol. 89, no. 1, pp. 138-149, 2015.

[23] H. Hiroyasu and M. Arai, "Structures of fuel sprays in diesel engines," in Proceedings of the International Congress \& Exposition, SAE Paper, Detroit, MI, USA, February 1990.

[24] D. L. Siebers, "Scaling liquid-phase fuel penetration in diesel sprays based on mixing-limited vaporization," in Proceedings of the International Congress \& Exposition, SAE Paper, Michigan, Detroit, USA, March 1999.

[25] J. M. Desantes, R. Payri, F. J. Salvador et al., "Development and validation of a theoretical model for diesel spray penetration," Fuel, vol. 85, no. 7-8, pp. 910-917, 2006.

[26] F. Payri, J. V. Pastor, J. M. Pastor, and J. E. Juliá, “Diesel spray analysis by means of planar laser-induced exciplex fluorescence," International Journal of Engine Research, vol. 7, no. 1, pp. 77-89, 2006.

[27] X. Wang, Z. Huang, O. A. Kuti, W. Zhang, and K. Nishida, "Experimental and analytical study on biodiesel and diesel spray characteristics under ultra-high injection pressure," International Journal of Heat and Fluid Flow, vol. 31, no. 4, pp. 659-666, 2010. 